\title{
Challenges of Diffusion Bonding of Different Classes of Stainless Steels
}

\author{
Thomas Gietzelt,* Volker Toth, and Andreas Huell
}

Solid state diffusion bonding is used to produce monolithic parts exhibiting mechanical properties comparable to those of the bulk material. This requires diffusion of atoms across mating surfaces at high temperatures, accompanied by grain growth. In case of steel, polymorphy helps to limit the grain size, since the microstructure is transformed twice. The diffusion coefficient differs extremely for ferritic and austenitic phases. Alloying elements may shift or suppress phase transformation until the melting range. In this paper, diffusion bonding experiments are reported for austenitic, ferritic, and martensitic stainless steels possessing varying alloying elements and contents. Passivation layers of different compositions are formed, thus affecting the local diffusion coefficient and impeding diffusion across faying surfaces. As a consequence, different bonding temperatures are needed to obtain good bonding results, making it difficult to control the deformation of parts, since strong nonlinearities exist between temperature, bonding time, and bearing pressure. For martensitic stainless steel, it is shown that it is very easy to obtain good bonding results at low deformation, whereas ferritic and austenitic stainless steels require much more extreme bonding parameters.

\section{Introduction}

Diffusion bonding is a special joining technique requiring expensive equipment. Usually, it is accomplished in batches. Despite these disadvantages, it is widely spread in aerospace industries for production of thin sheet structures or special applications where other joining techniques fail. ${ }^{[1-3]}$ Advantages and disadvantages are summarized, for example, in ref.[4] Diffusion bonding is the only welding technique that can be used to produce holohedral joints also of internal structures. In contrast to common welding techniques, no heat-affected zone (HAZ) is formed. However, the whole parts are subjected to a heat treatment. ${ }^{[5]}$ Furthermore, bonding is achieved in the solid state, contrary to other welding techniques. Normally, diffusion bonding is carried out in high vacuum or under inert gas atmosphere at temperatures of about $80 \%$ of the solidus

Dr. T. Gietzelt, Dr. V. Toth, Dr. A. Huell

KIT, Institute of Micro Process Engineering, PoBox 3640, 76021

Karlsruhe

E-mail: thomas.gietzelt@kit.edu

The ORCID identification number(s) for the author(s) of this article can be found under https://doi.org/10.1002/adem.201700367.

DOI: 10.1002/adem.201700367 temperature, at which the diffusion coefficient is high enough to achieve joining within a technically reasonable period of time. To obtain good diffusion bonding results, appropriate roughness of surfaces is required. External pressure is applied for leveling surface roughness and tobring surfaces into atomic contact so that diffusion can take place. The contact area is extended by diffusion along grain boundaries, since the atomic density there is lower than in the metallic lattice. Finally, when a certain contact area value is reached, volume diffusion becomes predominant, thus filling the remaining pores.

The long time needed for diffusion also is the reason why undesired secondary effects are encountered in complex alloys, such as sensitization of nickel-base alloys. Due to the higher diffusion coefficient, impurities, for example, carbon, form precipitations with, for example, chromium and molybdenum at grain boundaries, thus decreasing corrosion resistance and causing intergranular corrosion.

Sometimes, additional interlayers of different materials are used. They often have a lower melting temperature or form a temporary liquid phase of eutectic composition. As a result, the diffusion coefficient is considerably increased locally and formation of the bond is supported. ${ }^{[6-8]}$

Interlayers can be fabricated by employing, for example, thin foils, electrodeposition, or physical vapor deposition. Often, this temporary liquid phase disappears with time, since local composition is changed by diffusion. However, this may damage the microstructure by predominant diffusion along grain boundaries and adversely affects corrosion properties.

In some article, diffusion bonding experiments are reported, where an interlayer remains after the bonding process. Hence, joining is accomplished mainly by leveling surface roughnesses and a two-phase material is formed. Although the leak rate may be very good, the parts suffer from insufficient mechanical and corrosion properties far below those of the bulk material. Strictly speaking, it is a kind of soldering, but no diffusion bonding, since diffusion involving the bulk material is inadequate. ${ }^{[9]}$

Hence, the question arises which criteria have to be met for diffusion bonding to be successful. First, the mechanical properties of bonded samples should reach those of the bulk material. For this, secondly, the part should exhibit a singlephase microstructure only. The third requirement to achieve this is grain growth across the bonding planes. To fulfill these 


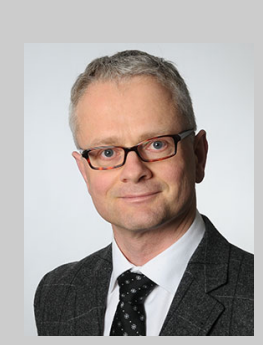

T. Gietzelt studied material science at TU Dresden and received his PhD at "Leibniz Institute of Polymer Research Dresden e.V." in 1997. Afterwards he was a Post Doc at "Forschungszentrum Karlsruhe", "Institute of Materials Research III", developing a powder injection molding process for ceramic microparts. In 2002 he changed to "Institute for Micro Process Engineering" as a group leader for micro machining of micro injection and embossing tools as well as microfluidic devices. Recently his research interests at "Karlsruhe Institute of Technology" are laser cutting, laser welding, diffusion bonding and corrosion phenomena's in micro process apparatuses.

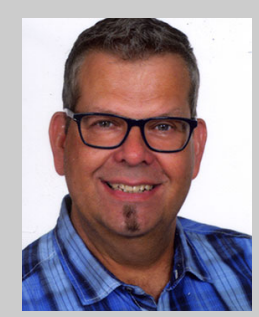

V. Toth finished his apprenticeship as precision mechanic in 1989 at "Forschungszentrum Karlsruhe". Afterwards, he worked as an operator at the hot cells, handling radioactive substances. From 1994 to 1996 he attended school doing his technician. In 1996 he changed to "Institute for Micro Process Engineering". Since than he is dealing with adapting diffusion bonding according to special requirements of microstructured process devices and optimization of process parameters.

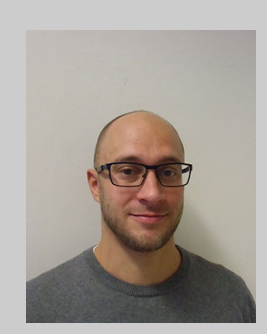

A. Huell finished his vocational training as a precision mechanic, at "Forschungszentrum Karlsruhe" in 1999. Afterwards, he worked as a CNC programmer at the "Department for Experimental Technics", dealt with mechanically micromanufacturing and machined components for microstructured devices. In 2006, he changed to the "Institute for Micro

Process Engineering", performing diffusion bonding of microstructured process devises, as well as optimizing bonding parameters for different materials.

conditions, high temperatures are necessary, with the diffusion coefficient being high enough to complete the process within a technically reasonable period of time.

It is obvious that diffusion of atoms inside a volume of material at high temperatures also involves diffusion along grain boundaries. Hence, diffusion bonding always is associated with grain growth, as long as the material shows no polymorphy. Especially for different sorts of steel, the coefficient of diffusion may vary by several orders of magnitude depending on whether the lattice is of fcc (face-centered cubic; austentic) or bcc (body centered cubic; ferritic) type. In case of a polymorphic material, the material's microstructure is changed twice, during heating up and cooling down, thus annihilating grain growth during diffusion bonding. In the fcc lattice of steels, a much higher solubility but lower diffusion coefficient, for example, for carbon, is encountered. Some alloying elements, however, may stabilize the austenitic or ferritic phase until the melting range. This especially applies to stainless steels, whose corrosion resistance is based on a stable passivation layer. For passivation layers, the coefficient of diffusion is much lower. Contrary to titanium, the passivation layers of stainless steels are insoluble in the matrix materials at high temperatures, which impedes diffusion of atoms locally across bonding planes. ${ }^{[10]}$ Furthermore, thermal stability of the passivation layer depends on the type and the amount of alloying elements. Depending on the required corrosion resistance and application, it varies for different sorts of stainless steel. Consequently, different temperatures and dwell times are required for different alloys to achieve grain growth across faying surfaces.

The bonding temperature for diffusion kinetics interacts very sensitively with the bearing pressure for leveling surface roughness and for bringing surfaces into atomic contact, which determines deformation during diffusion bonding. If the temperature must be increased to overcome inhibition of diffusion across passivation layers, it is very difficult to control deformation due to its strong nonlinearity.

Ideally, the original layers cannot be detected anymore after successful diffusion bonding. Parts are found to assume the mechanical properties of bulk material subjected to the same heat treatment.

Since the process is mostly performed under vacuum, the maximum cooling rate after diffusion bonding depends on the mass and size of parts as well as on the size of the bonding furnace. These factors may especially decrease the corrosion behavior of materials, since precipitations can be formed and intergranular attack may occur without any subsequent appropriate heat treatment.

In case of sufficient carbon content, the cooling rate affects the material's microstructure together with the alloying elements. Time-temperature-transformation diagrams (TTT diagrams) apply to these sorts of steel. ${ }^{[11]}$

These issues are addressed by this paper. Appropriate values for bonding temperature and dwell time are determined for different sorts of stainless steel.

\section{Materials and Design}

\subsection{Material Science Background of Steel - Solubility of Carbon}

Steel is the most commonly used class of metallic alloys. The quantity consumed has exceeded 1.6 billion tons per year since 2013. ${ }^{[12]}$ Several thousand different alloys can be found in the Stahlschlüssel, along with a wide range of properties for different requirements and applications. ${ }^{[13]}$ A large number of alloying elements are employed to considerably change the properties of iron, the most important of them being carbon, which is also due to its low cost. The iron-carbon phase diagram (Figure 1) is 


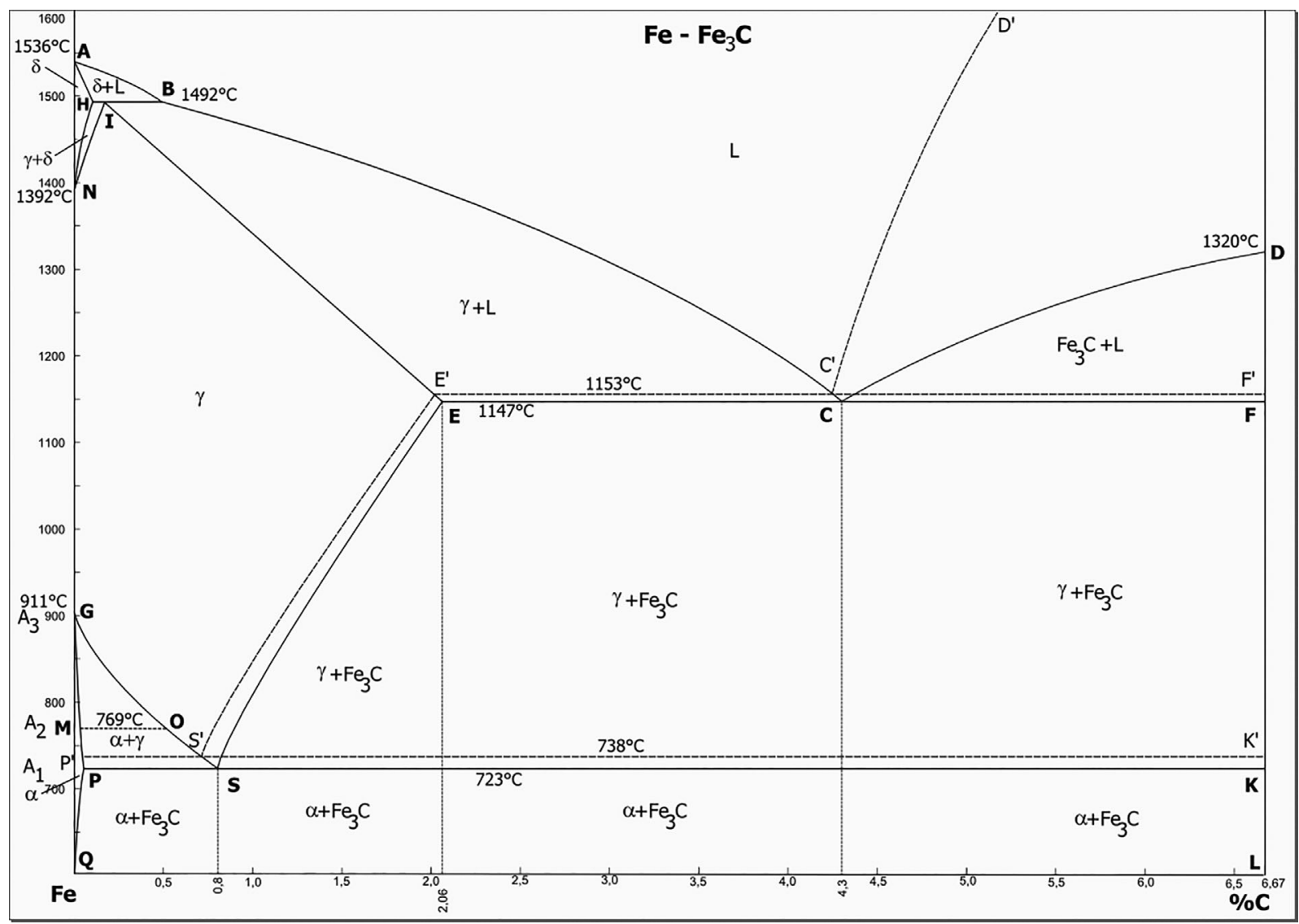

Figure 1. Fe-C diagram. Dashed lines illustrate the stable $\mathrm{Fe}-\mathrm{C}$ state, continuous lines the metastable (technical) $\mathrm{Fe}-\mathrm{Fe}_{3} \mathrm{C}$ state. ${ }^{[14]}$

well-known. However, it can be applied for technical equilibrium conditions only. In practice, non-equilibrium states are encountered frequently, for example, after heat treatments, and TTT diagrams vary for each steel alloy.

According to Figure 1, the area of steel is limited to $2.06 \mathrm{wt} \%$ of carbon, corresponding to the maximum solubility of the facecentered cubic (fcc) austenite at $1420 \mathrm{~K}\left(1147^{\circ} \mathrm{C}\right)$. The bodycentered cubic (bcc) ferrite, however, has a maximum carbon solubility of $0.02 \mathrm{wt} . \%$ at $996 \mathrm{~K}\left(723^{\circ} \mathrm{C}\right)$ only. Increasing carbon contents reduce both the liquidus and solidus temperatures. At $4.3 \mathrm{wt} \%$ carbon and $1420 \mathrm{~K}\left(1147^{\circ} \mathrm{C}\right)$, a eutectic is formed, whose melting point is $393 \mathrm{~K}$ lower than that of pure iron. Finally, at $6.67 \mathrm{wt} \%$ carbon, $100 \%$ of the intermetallic phase $\mathrm{Fe}_{3} \mathrm{C}$ is formed. Higher carbon contents are technically irrelevant.

Furthermore, it can be seen that carbon also reduces the transition temperature from fcc austenite to bcc ferrite from $1184 \mathrm{~K}\left(911^{\circ} \mathrm{C}\right)$ for pure iron to a minimum of $996 \mathrm{~K}\left(723^{\circ} \mathrm{C}\right)$ at $0.8 \mathrm{wt} \%$ of carbon. At this carbon content, the eutectoid grain disintegrates to a $100 \%$ perlitic microstructure, consisting of intragranular lamellas of $\mathrm{Fe}_{3} \mathrm{C}$ and ferrite.

\subsection{Impact of Additional Alloying Elements}

Some alloying elements, such as silicon and manganese which have similar atom sizes and the same types of lattice, can form solid solutions with iron. Other alloying elements like chromium, vanadium, tungsten, molybdenum, niobium, and titanium have a higher affinity to carbon than iron, forming other carbides and mixed carbide hard phases. Hence, some steels with more than $2.06 \mathrm{wt} \%$ carbon can be found, for example, in the class of cold work tool steels like X210Cr12 (1.2080).

It is not easy to predict percentages of phases from the $\mathrm{Fe}-\mathrm{C}$ diagram, since carbon partly captures these alloying elements and forms own carbides. Efforts have been made to calculate the developing phases by means of thermodynamic approaches. Several programs are available to model the amount of appearing phases. ${ }^{[15,16]}$

Alloying elements also increase the hardening depth for thickwalled parts by reducing the critical rate of cooling to form martensite. $^{[17]}$

Alloying elements may have an impact on phase transformation, as they can stabilize ferrite or austenite, see section 2.2.2.

\subsubsection{Mild Steel and Low-Alloyed Steel}

Often, the parameters of relevance to practical use are mechanical properties, such as yield or tensile strength and strain to rupture. Different mechanical properties may result at the same chemical composition, for example, due to cold work 


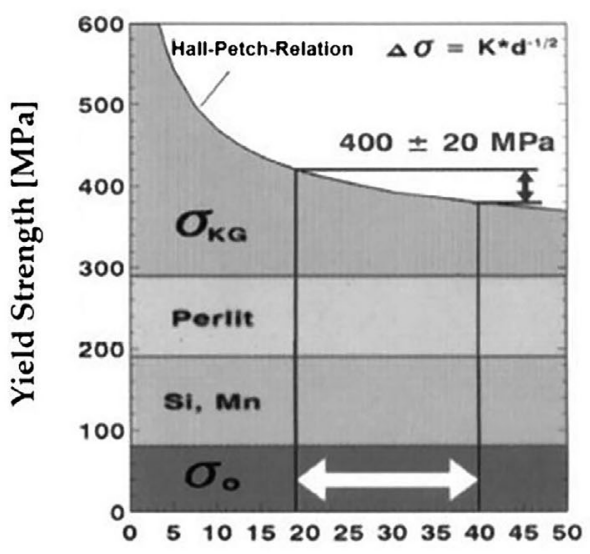

a) Grain Size $[\mu \mathrm{m}]$

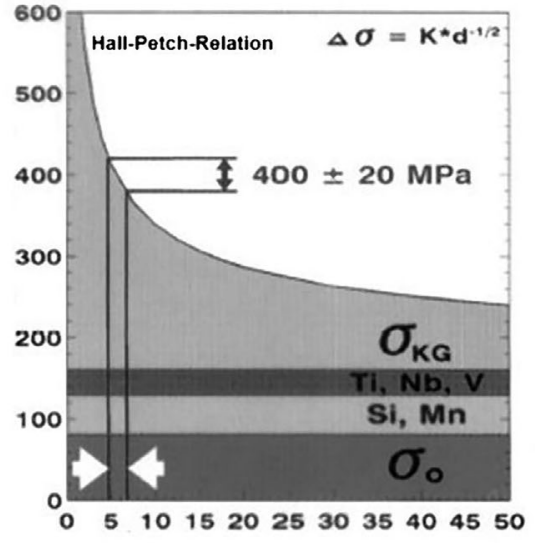

b) Grain Size $[\mu \mathrm{m}]$

Figure 2. Constant yield strength of construction steels exploiting the Hall-Petch relation to decrease grain sizes and the carbon content for improved weldability. Left: Conventional construction steel. Right: Microalloyed fine-grained construction steel.

hardening, thermomechanical treatment with strain hardening and recrystallization taking place at once, or other heat treatments. However, the degree of cold work hardening also affects the remaining strain to rupture. As a consequence, mild steels of high strength have reduced strains to rupture.

Due to the polymorphy, the grain size can be adjusted without cold deformation and subsequent recrystallization by a simple oscillating heat treatment around the ferrite-austenite transition temperature. A new microstructure is formed whenever phase transition takes place. In this way, the Hall-Petch relationship of small-grained materials can be exploited by ultrafine-grained mild steels (Figure 2). ${ }^{[18-20]}$

Usually, construction steels are far below the eutectoid composition of $0.8 \mathrm{wt} \%$ of carbon for a $100 \%$ perlitic microstructure, since carbon reduces weldability. In fact, the carbon content is below $0.2 \mathrm{wt} \%$ to guarantee good weldability. ${ }^{[21]}$ Currently, applied ultrafine-grained construction steels are microalloyed and form precipitations of special carbides and nitrides that are finely distributed across the grain matrix (using $\mathrm{Ti}, \mathrm{Nb}, \mathrm{V}$, right in Figure 2) and impede grain growth. Iron atoms in the lattice are replaced by manganese and silicon, which influences the mechanical properties by solid solution hardening.

Also other low-alloyed steels are well suited for diffusion bonding, since they exhibit a polymorphic behavior and do not form any stable surface layers. As the diffusion coefficient of iron for a body-centered cubic lattice is about two orders of magnitude higher than for the face-centered cubic austenite, the diffusion bonding temperature should be below the phase transition temperature (Figure 3). After bonding, the temperature must be increased to initialize lattice transformation, and a new microstructure of the material is formed twice, during heating and cooling down below the transition temperature.

As can be seen from Figure 3, smaller atoms have much higher diffusion coefficients in iron. Due to slow cooling rates after diffusion bonding, a subsequent heat treatment may be necessary to obtain the desired microstructures, for example, to dissolve precipitations at grain boundaries or to perform solution annealing, hardening, and annealing.

\subsubsection{Sorts of Stainless Steel}

When referring to high-grade steel, mostly austenitic stainless steels are considered. As obvious from Figure 4, however, different types of stainless steels must be distinguished: Depending on the carbon content and phase transformation behavior resulting from the types and contents of additional alloying elements used, also martensite may be formed. Other alloying elements act like nickel or chromium, which is summarized by nickel and chromium equivalents (Figure 4).

Whereas nickel stabilizes austenite, chromium does for ferrite (Figure 5).

Also other approaches were developed to estimating and predicting the amount of appearing phases for stainless steels, for example, DeLong and WRC diagrams. ${ }^{[25,26]}$

Stainless steel contains a minimum of $13 \mathrm{wt} \%$ chromium that forms a passivation layer with a high content of chromium oxide at the surface. More about the thickness of $1-5 \mathrm{~nm}$ of the passivation layer and its composition in terms of other alloying elements can be found in literature. ${ }^{[27,28]}$ In Figure 5 on the right, it can be seen how the addition of $13 \mathrm{wt} \%$ chromium affects the

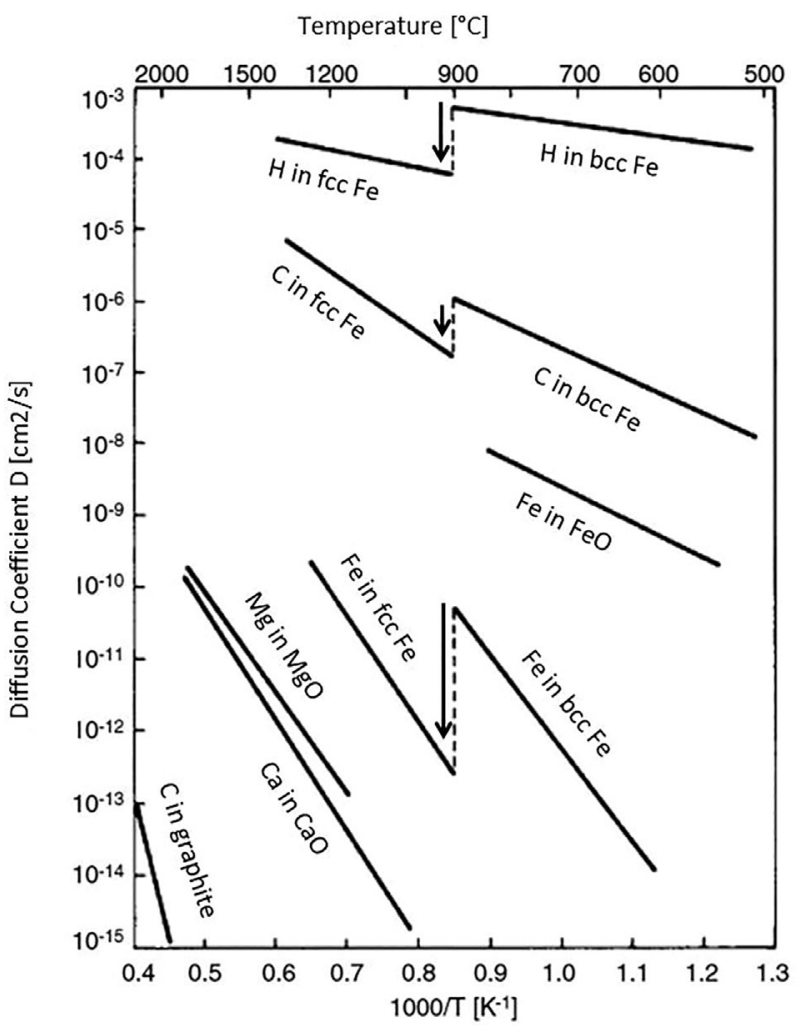

Figure 3. Diffusion coefficient depending on the type of lattice and atom size. $^{[22,23]}$ 


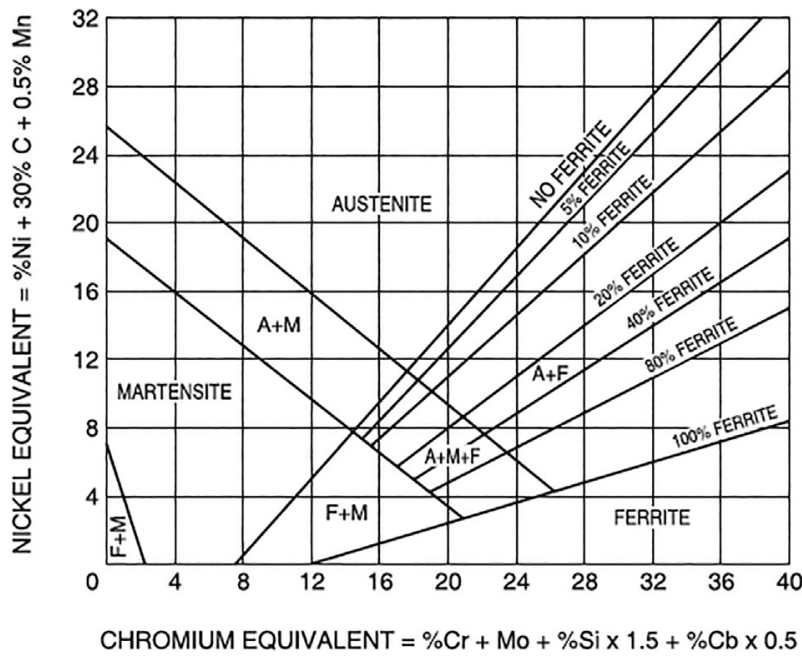

Figure 4. Schaeffler diagram for different sorts of stainless steels containing different amounts of martensitic, ferritic, and austenitic phases depending on the alloying elements used. ${ }^{[24]}$

phase transition from ferrite to austenite depending on the carbon content.

For the martensitic steel 1.4021 (X20Cr13), diffusion bonding below $815^{\circ} \mathrm{C}$ is possible in the range of the ferritic microstructure at a high diffusion coefficient (cf. Figure 3).

Since all these phase diagrams reflect thermodynamic equilibrium, it has to be stated that inappropriate heat treatments may cause sensitization: For slow cooling rates or long dwell times in the range of $600-900^{\circ} \mathrm{C}$, carbides and Laves phases form precipitations at grain boundaries, thus causing intergranular corrosion in contact with corrosive liquid media. Taking into account that the thickness of passivation layers is in the low nanometer range, these precipitations cannot be covered.

\subsubsection{Martensitic Stainless Steels}

To form martensite, a certain carbon content is required. Since the solubility of carbon for fcc austenite is about one hundred times higher than for bcc ferrite, carbon is precipitated as iron carbides, so-called cementite, according the iron-carbon phase diagram under thermodynamic equilibrium conditions. At fast cooling rates, diffusion of carbon out of the fcc austenite can be suppressed, despite the much higher diffusion coefficient for small atom sizes. As a consequence, the cubic unit cell of bcc ferrite is distorted to tetragonal, and a structural change occurs without any diffusion of atoms. High internal stress of martensite causes a strong increase of hardness and decreases the strain to rupture. Subsequent annealing is required to adjust these mechanical properties as desired.

However, additionally alloying elements may considerably influence the cooling rate necessary for martensite formation by lattice distortion due to solid solution hardening effects. ${ }^{[32]}$

In case of martensitic stainless steel X20Cr13 (1.4021), for example, the $13 \%$ of chromium and $0.2 \%$ of carbon make the phase transition temperature from ferrite to pure austenite rise, as is obvious from Figure 5 on the right. A hardening temperature between 950 and $1050^{\circ} \mathrm{C}$ is recommended. ${ }^{[33]}$ Depending on the cooling rate, quite different microstructures and mechanical properties can be obtained. Even at very low cooling rates does the chromium content facilitate the formation of martensite, as is evident from the time-temperature transformation diagram. A hardening depth of $300 \mathrm{~mm}$ can be reached for 1.4021 (Figure 6). ${ }^{[34]}$ Furthermore, the ferrite-austenite phase transition takes place twice, a new microstructure is formed, grain growth is annihilated, and formation of a monolithic compound across bonding planes is supported.

The influence of the critical cooling rate is of special interest to diffusion bonding, since the cooling rates in high vacuum are comparatively low, depending on the size of the parts to be welded and equipment of furnaces. For 1.4021, however, a cooling rate of approximately $3.5 \mathrm{~K} \mathrm{~min}^{-1}$ is sufficient to obtain martensite. The institute owns three furnaces of different sizes and maximum loads of 20,200 , and $200 \mathrm{kN}$, respectively. The cooling rate between $1100-300^{\circ} \mathrm{C}$ is $6.1,2.35$, and $1 \mathrm{~K} \mathrm{~min}^{-1}$, respectively. Hence, martensite for 1.4021 can be produced in the smallest furnace only.

In terms of corrosion resistance, it has to be mentioned that, since the affinity of chromium to carbon is higher than it is for iron, some chromium may be absorbed in $(\mathrm{Cr}, \mathrm{Fe}){ }_{23} \mathrm{C}_{6}$ carbides, as is shown in Figure 10. As a consequence, not all chromium is available to form a stable chromium oxide passivation layer at the surface, and corrosion resistance of martensitic stainless steels is lower than that of austenitic stainless steels.

\subsubsection{Ferritic Stainless Steels}

For steels having a high chromium content of more than $18 \%$ and low carbon contents, hardening is not possible (Figure 5, right). For Crofer 22 APU (1.4760, X1CrTiLa22) containing 22\% chromium and no nickel, for example, phase transformation to fcc austenite is suppressed completely up to the melting range.

Regarding diffusion bonding, it is important to consider not only the much higher diffusion coefficient in ferrite (Figure 3) and, hence, increased deformation under a certain bearing pressure, but also an increase in the solidus temperature of about $100 \mathrm{~K}$ compared to austenitic stainless steels. ${ }^{[36]}$ At the same time, the passivation layer is very stable, thus preventing grain growth across the bonding planes. Hence, the discrepancy between a high plasticity at low temperatures and the high temperatures needed to overcome inhibition of diffusion across bonding planes by the passivation layers has to be balanced. Moreover, grain growth during diffusion bonding may be an issue, since no phase transformation occurs.

\subsubsection{Austenitic Stainless Steels}

Corrosion-resistant austenitic stainless steels often contain about $18 \%$ chromium and 8 or $10 \%$ nickel. Sorts with higher chromium and nickel contents, for example, for highly heat-resistant alloys like X10NiCrAlTi32-20 (1.4876), are available as well.

Since titanium has a strong affinity to carbon, it stabilizes stainless steels by forming own carbides. Examples are X6CrNiTi18-10 (1.4541) and X6CrNiMoTi17-12-2 (1.4571). Addition of molybdenum, for example, for 1.4571, improves the resistance against pitting corrosion. 

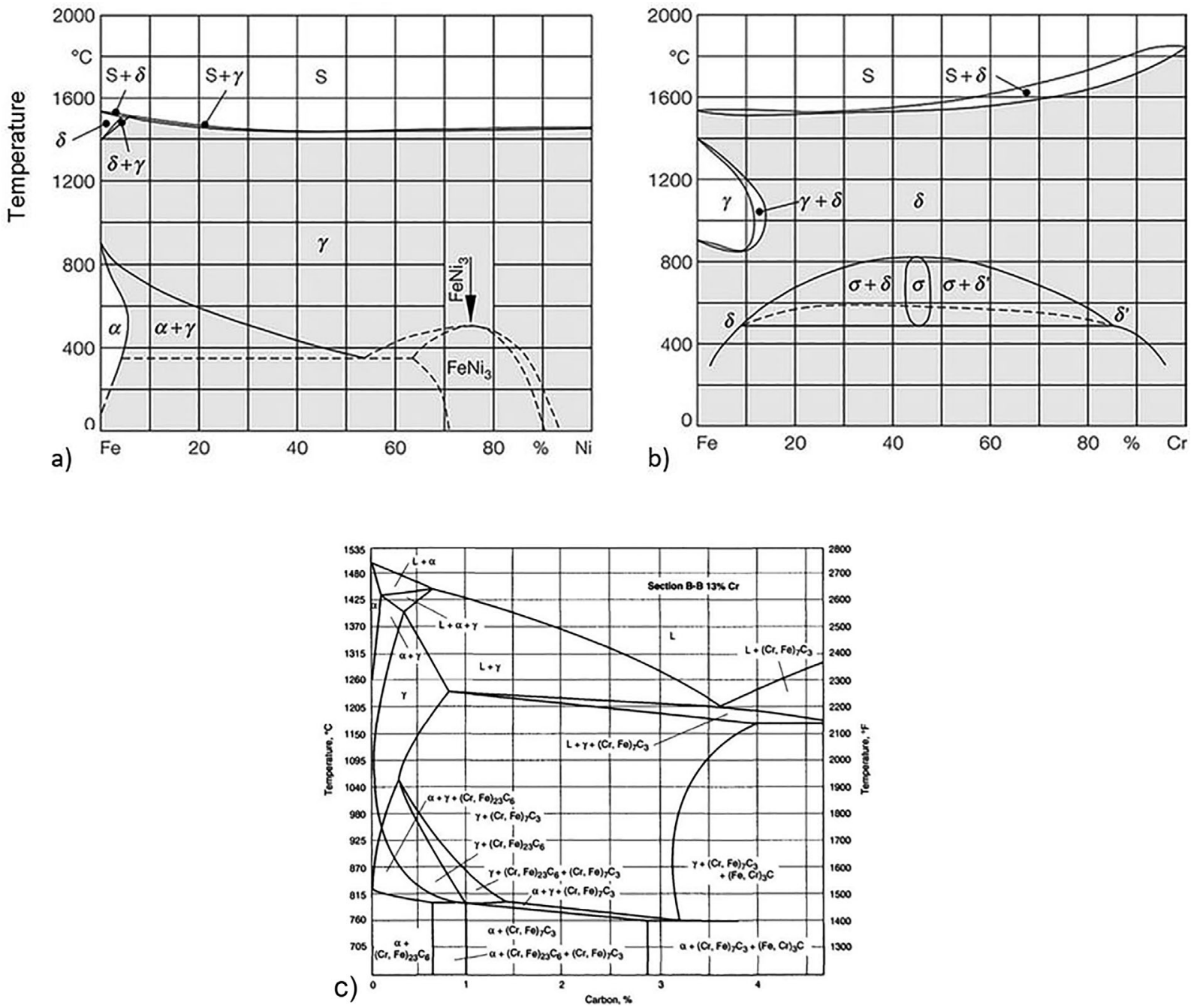

Figure 5. Impact of alloying elements on phase transition of iron: Impact of $\mathrm{Ni}$ a) and $\mathrm{Cr}$ b). ${ }^{[29,30]}$ The vertical section of the $\mathrm{Fe}-\mathrm{C}$ diagram at $13 \mathrm{wt} \% \mathrm{Cr}$ is shown on the c) ${ }^{[3]]}$

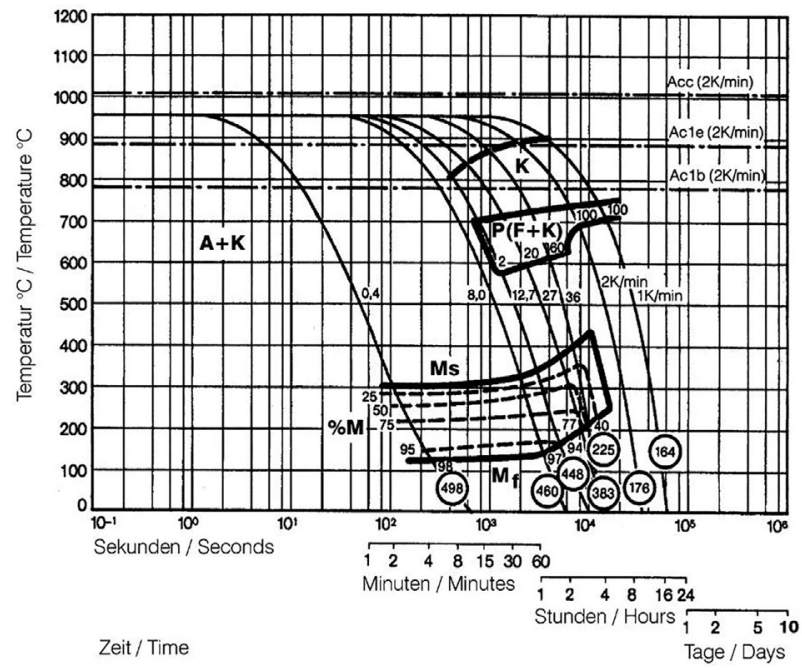

Figure 6. Time-temperature transformation diagram for $1.4021 .^{[35]}$
Due to the high and fluctuating price of nickel, austenitic stainless steels were developed, in which nickel was replaced by manganese. An example is X8CrMnN18-18 (1.3816).

For diffusion bonding of austenitic stainless steels, much higher temperatures are required, due to the much lower diffusion coefficient of the bcc lattice (Figure 3). As a consequence, excessive grain growth takes place. As for ferritic stabilized stainless steels, no phase transformation occurs, and large grain sizes must be accepted.

Moreover, deformation is much lower than for ferritic steels and bearing pressures must be set to higher levels to achieve appropriate leveling of surface roughness.

\subsection{Role of Passivation Layers}

An important issue for diffusion bonding is thermal stability of the passivation layers, if present: For construction steel, surface layers are no obstacle and diffusion bonding is easy, which is also 
Table 1. Overview of parameters affecting diffusion bonding of different sorts of steel.

\begin{tabular}{|c|c|c|c|c|c|c|}
\hline $\begin{array}{l}\text { Property } \rightarrow \\
\text { Sort of Steel } \downarrow\end{array}$ & $\begin{array}{l}\text { Diffusion } \\
\text { Coefficient }\end{array}$ & $\begin{array}{l}\text { Bonding } \\
\text { Temperature }\end{array}$ & $\begin{array}{l}\text { Bonding } \\
\text { Pressure }\end{array}$ & $\begin{array}{l}\text { Deformation } \\
\text { Behavior }\end{array}$ & $\begin{array}{l}\text { Passivation } \\
\text { Layer }\end{array}$ & $\begin{array}{l}\text { Grain } \\
\text { Growth }\end{array}$ \\
\hline 1. Mild Steel ${ }^{\text {a) }}$ & $\uparrow$ & $\downarrow$ & $\downarrow$ & $\uparrow$ & $\downarrow$ & $\downarrow$ \\
\hline 2. Austenitic Stainless Steel & $\downarrow$ & $\uparrow$ & $\uparrow$ & $\downarrow$ & $\uparrow$ & $\uparrow$ \\
\hline $\begin{array}{l}\text { 3. Other High-alloyed Austenitic Alloys (e.g., Heat-resistant SS, } \\
\text { Ni-base Alloys) b) }\end{array}$ & $\downarrow$ & $\Uparrow$ & $\uparrow$ & $\downarrow$ & $\Uparrow \uparrow$ & $\Uparrow$ \\
\hline 4. Ferritic Stainless Steel & $\uparrow$ & $\downarrow$ & $\downarrow$ & $\uparrow$ & $\uparrow$ & $\Uparrow$ \\
\hline 5. Martensitic Stainless Steel a) & $\uparrow$ & $\downarrow$ & $\downarrow$ & $\uparrow$ & $\uparrow$, less than 2 . & $\downarrow$ \\
\hline
\end{tabular}

a) After diffusion bonding in the ferritic range, the temperature should be raised to the uniform austenite area, and precipitated carbides can be dissolved. By forming a new microstructure twice, grain growth is suppressed.

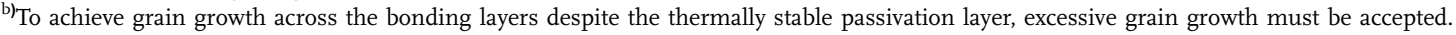

due to phase transformation. For high-alloyed steels, however, passivation layers may have various compositions, properties, and thicknesses depending on the composition of the alloy. Some alloying elements used for heat-resistant steels, namely, silicon and aluminum, form dense layers preventing metal dusting by further oxidation, carburization, or sulfation of the base material depending on the operation atmosphere. Especially steels containing more than $1 \%$ of these elements are difficult to join.

The opposite is true, for example, for titanium alloys, where the oxide is highly soluble in the matrix. However, it has to be kept in mind that titanium grades 1 to 4 differ only slightly in oxygen content. Still, these differences have a huge impact on mechanical strength. When joining thin sheet materials of some hundred micrometers in thickness in microsystems technology, the material afterwards may have a different oxygen content.

The oxides of the passivation layers of stainless steels, namely, chromium and nickel oxides, are not soluble in the matrix material. Due to the varying alloy compositions of stainless steels and depending on the nature of the passivation layers, the diffusion bonding temperature must be raised to different levels to overcome inhibition of diffusion across the bonding planes.

\subsection{Summary}

In case of steels, some remarkable differences can be noticed, which require different sets of parameters for diffusion bonding. The parameters in Table $\mathbf{1}$ have to be assessed qualitatively in terms of the relation and interaction of temperature, bearing pressure, and deformation. Moreover, the nature of the passivation layer has to be taken into account.

\section{Experimental and Discussion}

Practical examples of diffusion bonding of different sorts of steels are shown in Figure 7-9. Bonding planes are marked by arrows. A satisfying result with grain growth across the bonding plane at reasonable deformation could not be obtained for all alloys, and further optimization is necessary.
A summary of the chemical compositions of the alloys used is given in Table 2 .

Normal austenitic stainless steel of the 18-8 type can be diffusion-welded relatively easily with reasonable results. However, temperature and bearing pressure are higher than known for mild steel due to the reduced diffusion coefficient in the fcc lattice and stable passivation layers (Figure 7).

For higher alloyed austenitic stainless steels and nickel-base alloys, even higher temperatures and longer bonding durations are necessary to overcome the more stable passivation layer and to obtain grain growth across the bonding plane. Bearing pressure is reduced to compensate for increased creep rates.

The dynamics of grain growth of steels exhibiting no polymorphic behavior has not yet been investigated in detail. However, the impact of temperature can be seen clearly, for example in Figure 7-9.

Grain growth across the bonding plane, accompanied by a considerable increase of grain size, was observed in the ferritic Crofer 22APU (1.4760) at very high temperatures and for long durations (Figure 8) only. As can be seen from the experiments, thermal stability of the passivation layer is difficult to overcome in ferritic steel. This is mainly due to its composition and microstructure resulting from chromium and manganese despite of the high coefficient of diffusion in the bcc lattice. ${ }^{[37]}$

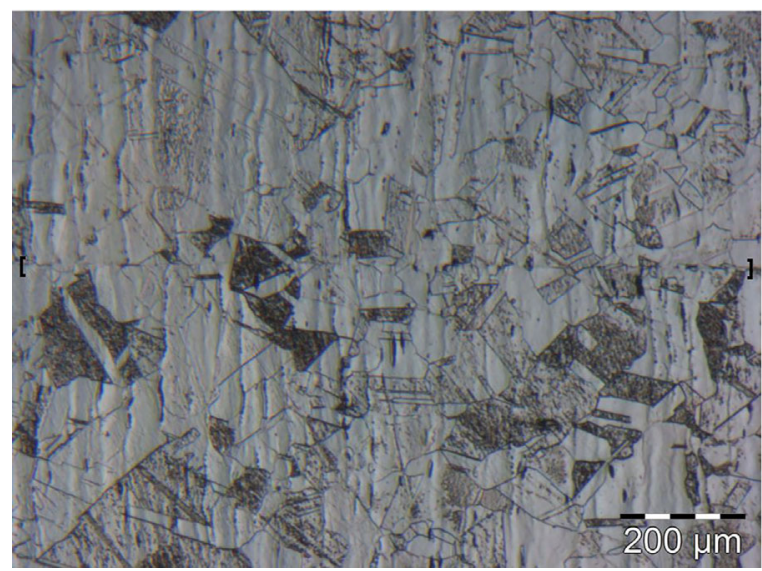

Figure 7. Diffusion bonding of $\mathrm{X} 5 \mathrm{CrNi} 18-10 \quad$ (1.4301). $T=1348 \mathrm{~K}$ $\left(1075^{\circ} \mathrm{C}\right), t=1 \mathrm{~h}, p=23 \mathrm{MPa}$. 

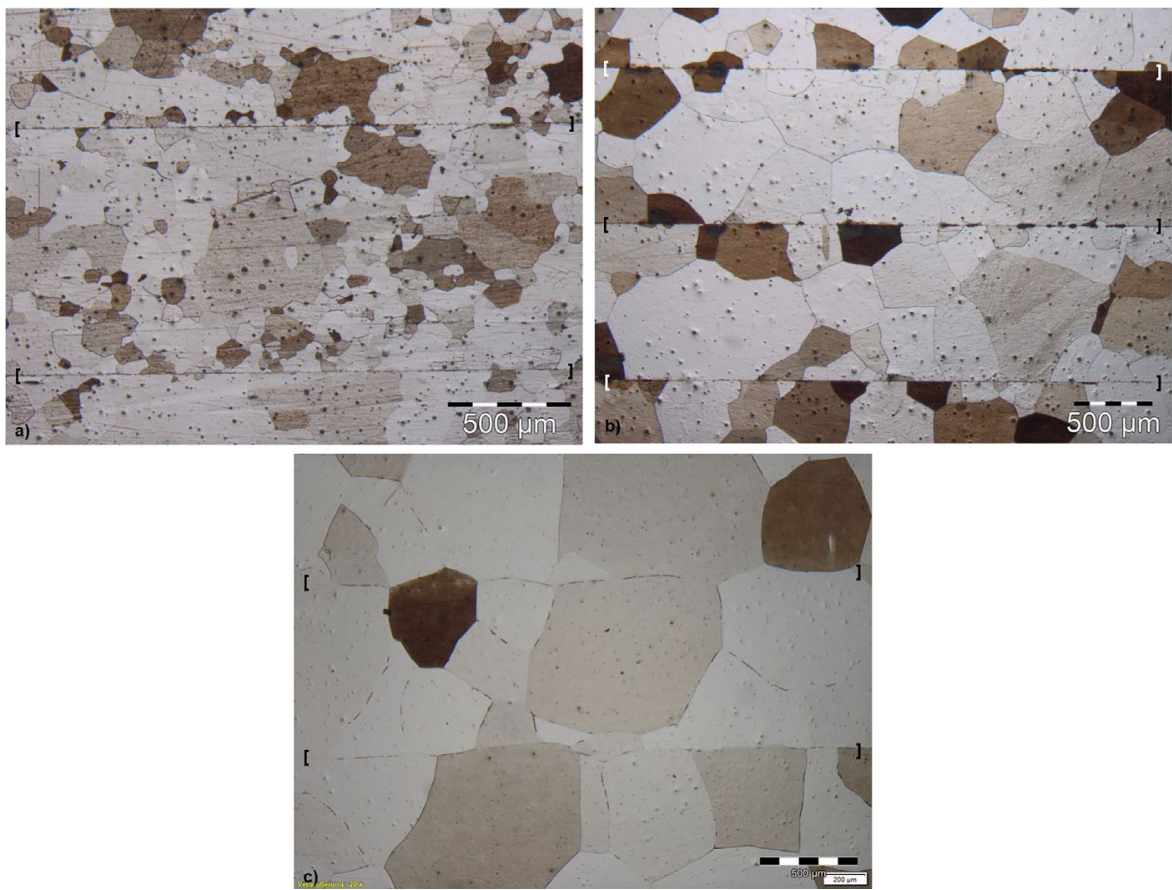

Figure 8. Diffusion bonding of ferritic stainless steel X1CrTiLa22 (1.4760). a): $T=1223 \mathrm{~K}\left(950^{\circ} \mathrm{C}\right), t=1 \mathrm{~h}$, $p=6 \mathrm{MPa}$. b): $T=1348 \mathrm{~K}\left(1075^{\circ} \mathrm{C}\right), t=1 \mathrm{~h}, p=3 \mathrm{MPa}$. c): $T=1548 \mathrm{~K}\left(1275^{\circ} \mathrm{C}\right), t=4 \mathrm{~h}, p=2 \mathrm{MPa}$.

precipitations are formed at the grain boundaries, together with martensite (cf. Figure 6).

\section{Results and Conclusions}

It was shown that diffusion bonding of steels is determined by numerous materials science aspects. Depending on the type of lattice and thermal behavior, very different parameters may be appropriate to form monolithic parts.

Also passivation layers may require the bonding temperatures to be set to much higher levels than required elsewhere.

Deformation depends not only on the material used and on the parameters of temperature, bearing pressure, and dwell time, but also on the aspect ratio and design of microstructured parts. For example, deformation may double or even triple for large, but very flat samples with higher aspect ratios. ${ }^{[38]}$

In addition, the percentage bonding cross section has an impact: At ambient temperature, deformation is controlled

Figure 9 shows excessive grain growth of the austenitic heatresistant stainless steel 1.4876 , when the bonding temperature is raised from 1200 to $1250^{\circ} \mathrm{C}$. Obviously, discontinuous grain growth takes place and separate giant grains are formed. Due to its higher contents of chromium, nickel, and additional elements, it forms a dense layer that prevents oxygen from diffusing inside and from forming a scale layer. As a result of the volume increase, scale layers tend to flake and metal dusting may occur.

For martensitic stainless steels, very good bonding results are obtained at low temperatures. Deformation is low. The polymorphic behavior that results from heating parts to the fully austenitic state after bonding gives rise to a new microstructure. Grain growth is reduced, while the formation of a monolithic part is supported. Due to retarded cooling in the furnace, some cementite by shear stress-induced movement of dislocations through the lattice. At high temperatures, however, deformation is controlled mainly by diffusion as a function of the density of vacancies, and a strong influence of grain size is found.

Whereas Coble creep takes place by diffusion of atoms along grain boundaries, which changes the shape of grains depending on external stress, Nabarro-Herring creep is highly dependent on temperature and is caused by diffusion of atoms (or vacancies) through the volume of grains. As can be seen for a nickel-base alloy containing 20 at\% chromium and having a grain size of $100 \mu \mathrm{m}$, the temperature and bearing pressure applied for diffusion bonding are in the range, where deformation may change between both mechanisms. ${ }^{[39]}$

Hence, the deformation behavior is very sensitive and correlations of temperature, bearing pressure, and mechanical microstructure are strongly nonlinear. Hence, multiple tests for diffusion bonding are needed
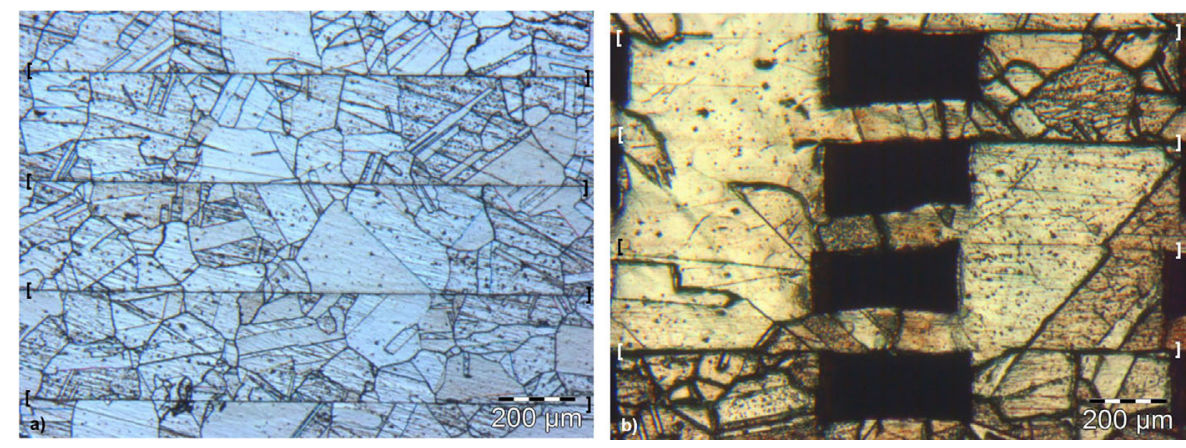

Figure 9. Diffusion bonding of $\times 10 \mathrm{NiCrAlTi} 32-20$ (1.4876). Left: $T=1473 \mathrm{~K} \quad\left(1200^{\circ} \mathrm{C}\right), t=4 \mathrm{~h}$, $p=8 \mathrm{MPa}$. Right: $T=1523 \mathrm{~K}\left(1250^{\circ} \mathrm{C}\right), t=4 \mathrm{~h}, p=5 \mathrm{MPa}$.
1) to ensure adequate grain growth for forming monolithic parts,

2) to limit grain growth of materials showing no polymorphic transition for technical reasons,

3) to limit deformation of parts to a reasonable amount,

4) to overcome thermally stable passivation layers, and

5) to determine the influence of internal microstructures on the deformation behavior. 

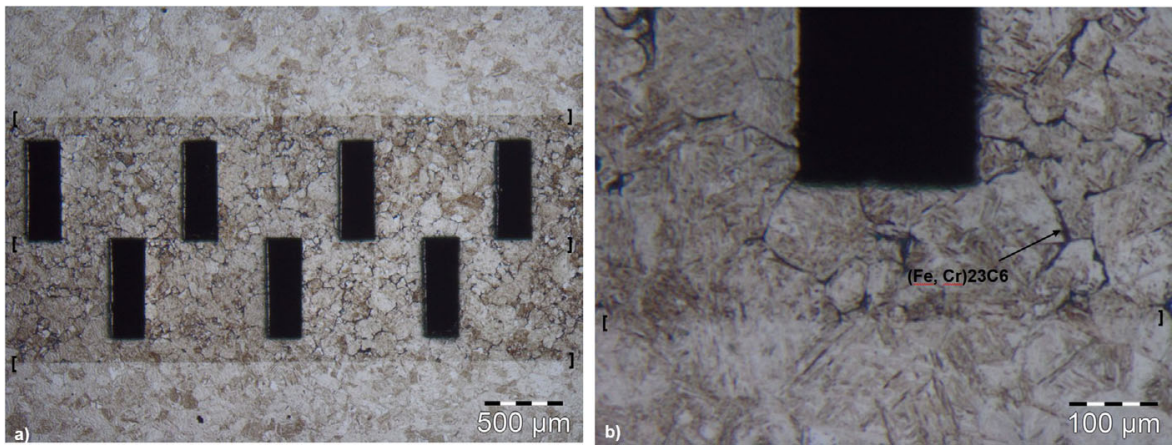

Figure 10. Diffusion bonding of $\mathrm{X} 20 \mathrm{Cr} 13(1.4021) . T=1223 \mathrm{~K}\left(950^{\circ} \mathrm{C}\right), t=1 \mathrm{~h}, p=17 \mathrm{MPa}$, followed by an austenitization step.

Diffusion bonding without deformation is not possible: It should be kept in mind that mating surfaces must be leveled for the formation of a monolithic part. Here, roughness parameters are important and can be specified for semi-finished products. ${ }^{[40]}$ Additionally, the evenness of a certain sheet thickness resulting from manufacturing processes like cold rolling is influenced by the absolute thickness, yield strength, and width of the material due to bending of the roll stand. Deviations across the width must be considered. ${ }^{[41,42]}$

Obviously, it is impossible to give a certain deformation value that is necessary during diffusion bonding to achieve vacuumtight sealing. Especially for multi-layered parts, the numbers of bonding layers must be considered, too.
Diffusion bonding always is a demanding skill, especially when bonding prototypes of different materials. For series production, parameters can be optimized. To decrease costs, however, bonding of multiple parts is desired. Depending on the size of the parts, it is important whether multiple parts are placed at one level or whether several parts must be placed at multiple levels, or both.

If so, parallelism of the dies may be distorted. This parallelism also depends on

Table 2. Compositions and melting ranges of alloys used for diffusion bonding experiments. ${ }^{[43]}$

\begin{tabular}{|c|c|c|c|c|c|}
\hline & 1.4021 & 1.4301 & 1.4760 & 1.4876 & 2.4602 \\
\hline & $\mathrm{X} 20 \mathrm{Cr} 13$ & $\mathrm{X} 5 \mathrm{CrNi} 18-10$ & X1CrTiLa22 & X10NiCrAlTi32-21 & $\mathrm{NiCr} 21 \mathrm{Mo} 14 \mathrm{~W}$ \\
\hline & martensitic & austenitic & ferritic & austenitic & austenitic \\
\hline $\mathrm{T}_{\mathrm{S}}[\mathrm{K}]$ & 1703-1773 & $1693-1743$ & 1783-1803 & $1623-1673$ & $1628-1673$ \\
\hline \multicolumn{6}{|c|}{ Element } \\
\hline C & $0.16-0.25$ & $<0.07$ & $<0.03$ & $\leq 0.12$ & $<0.01$ \\
\hline $\mathrm{Cr}$ & $12-14$ & $17.5-19.5$ & $20-24$ & $19-23$ & $20-22.5$ \\
\hline $\mathrm{Ni}$ & & $8-10.5$ & & $30-34$ & 50 \\
\hline $\mathrm{Mn}$ & $\leq 1.5$ & $<2.0$ & $0.3-0.8$ & $<2.0$ & $<0.5$ \\
\hline $\mathrm{Ti}$ & & & $0.03-0.2$ & $0.15-0.6$ & \\
\hline Mo & & & & & $12.5-14.5$ \\
\hline $\mathrm{Si}$ & $\leq 1.0$ & $<1.0$ & $<0.5$ & $<1.0$ & $<0.08$ \\
\hline $\mathrm{Cu}$ & & & $<0.5$ & & \\
\hline Co & & & & & $<2.5$ \\
\hline V & & & & & $<0.35$ \\
\hline W & & & & & $2.5-3.5$ \\
\hline $\mathrm{Al}$ & & & $<0.5$ & $0.15-0.6$ & \\
\hline $\mathrm{Fe}$ & bal. & bal. & bal. & bal. & \\
\hline La & & & $0.04-0.2$ & & \\
\hline$P$ & $\leq 0.040$ & $<0.045$ & $<0.05$ & $<0.03$ & $<0.025$ \\
\hline S & $<0.015$ & $<0.015$ & $<0.02$ & $<0.015$ & $<0.015$ \\
\hline $\mathrm{N}$ & & $<0.1$ & & & \\
\hline
\end{tabular}




\section{Acknowledgements}

Financial support under the Helmholtz Programme SCI (Storage Systems and Cross-linked Infrastructures) is gratefully acknowledged.

\section{Conflict of Interest}

The authors declare no conflict of interest.

\section{Keywords}

Diffusion bonding, diffusion welding, grain growth, passivation layer, stainless steel

Final Version: August 10, 2017 Received: April 19, 2017 Published online:

[1] H.-S. Lee, J.-H. Yoon, J.-T. Yoo, App. Mech. Mater. 2011, 87, 182.

[2] H.-S. Lee, K. J. Min, Key Eng. Mater. 2016, 689, 3.

[3] V. G. Novikov, Weld. Int. 1995, 9, 477.

[4] R. Rusnaldy, Jurusan Teknik Mesin, 2001, 3, 23. available from: http:// www.ejournal.undip.ac.id/index.php/rotasi/article/viewFile/2487/ 2199, [Accessed: 2017-07-20]

[5] J. Wilden, J. P. Bergmann, S. Jahn, W. Beck, DVS-reports 243 2010, p. 59.

[6] A. Laik, P. S. Gawde, K. Bhanumurthy, G. B. Kale, Metall. Mater. Trans. A 2008, 39A, 733.

[7] A. A. Shirzadi, E. R. Wallach, US 6669534 B2, 2003

[8] E. Akca, A. Gursel, Period Eng. Nat. Sci. 2015, 3, 12.

[9] P. S. Gawde, R. Kishore, A. L. Pappachan, G. B. Kale, G. K. Dey, Trans. Indian Inst. Met. 2010, 63, 853.

[10] N. F. Kazakov, Diffusions Bonding of Materials, Mir Publisher, Moscow 1985, p. 172.

[11] J. L. Dossett, H. E. Boyer, Practical Heat Treatment, Chapter 2, 2nd. Ed., ASM International, Materials Park, Ohio 2006 p. 23.

[12] Worldsteel Association, available from: https://www.worldsteel.org/ en/dam/jcr:1568363d-f735-4c2c-a 1da-e5172d8341dd/ World+steel+in+Figures+2016.pdf, p. 7, [Accessed: 2017-04-18]

[13] M. Wegst, C. Wegst, Stahlschlüssel-Taschenbuch 2016: Wissenswertes über Stähle, 24th Ed., Verlag Stahlschlüssel Wegst GmbH, Marbach 2016.

[14] Fe-C-diagram, available from: https://commons.wikimedia.org/ wiki/File\%3AFe-C.svg, [Accessed: 2017-07-03]

[15] J. Miettinen, S. Louhenkilpi, Metall. Mater. Trans. B 1994, 25B, 909.

[16] Thermo-Calc Software, available from: http://www.thermocalc.com/ solutions/by-material/iron-based-and-steels/ [Accessed: 2017-07-21]

[17] W. Seidel, F. Hahn, Werkstofftechnik, 10th rev. Ed., Carl Hanser Verlag, Munich 2014, p. 117

[18] U. Dilthey, Schweißtechnische Fertigungsverfahren 2, 3rd ed., Springer Berlin, Heidelberg, New York 2005, p. 98.

[19] J. Gobrecht, Werkstofftechnik - Metalle, 3rd ed., Oldenbourg Wissenschaftsverlag, Munich 2009, p. 128.

[20] Y. Weng, Ultra-Fine Grained Steels, Metallurgical Industry Press by Springer Berlin, Heidelberg, New York 2009, p. 3.
[21] H. Berns, W. Theisen, Eisenwerkstoffe - Stahl und Gusseisen, 3rd ed., Springer Berlin, Heidelberg, New York 2006, p. 153.

[22] G. Gottstein, Physikalische Grundlagen der Materialkunde, 3rd ed. Springer, Heidelberg, Dordrecht, London, New York 2007, p. 165.

[23] L. Schultz, J. Freudenberger: lecture Physikalische Werkstoffeigenschaften Physikalische Werkstoffeigenschaften, Kapitel 8: Diffusion, IFW Dresden, available from: http://www.ifw-dresden.de/userfiles/ groups/imw_folder/lectures/Physikalische_Werkstoffeigenschaften /c8-diff1.pdf [Accessed: 2017-07-24]

[24] E. Roos, K. Maile, Werkstoffkunde für Ingenieure, $4^{\text {th }}$ Ed. Springer Heidelberg, Dordrecht London, New York 2011, p. 157.

[25] D. J. Kotecki, T. A. Siewert, Weld. Res. Suppl. 1992, 171.

[26] D. L. Olson, Weld. Res. Suppl. 1985, 281.

[27] H. Kaesche, Die Korrosion der Metalle, 3rd, supplemented Ed., Springer Heidelberg, Dordrecht London, New York 2011, p. 225.

[28] K.-H. Grote, J. Feldhusen, Dubbel - Taschenbuch für den Maschinenbau, 22nd Ed., Springer Berlin Heidelberg, New York 2007, p. E91.

[29] H.-J. Bargel, G. Schulze, Werkstoffkunde für Ingenieure, 11th Ed., Springer Heidelberg, Dordrecht London New York 2012, p. 269.

[30] Fe-Cr-diagram, see under http://www.calphad.com/iron-chromium. html, [Accessed: 2017-04-18]

[31] K. Bungardt, E. Kunze, E. Horn, Arch. Eisenhüttenwes. 1958, 29, 193.

[32] Stahl-Informationszentrum, information sheet No. 452, p. 20, see under http://www.stahl-online.de/wp-content/uploads/2013/10/ MB-452-Einsatzhaerten.pdf [Accessed: 2017-04-18]

[33] Data sheet of 1.4021 given by DEUTSCHE EDELSTAHLWERKE $\mathrm{GMBH}$, see under http://www.thyssenkrupp.at/files/rsh/Werksto ffdatenblaetter/Stabstahl-Edelstahl-Rostfrei/1.4021.pdf [Accessed: 2017-04-18]

[34] Gruppo Lucefin, brochure, Stainless Steels, p. 41, Available from: http://www.lucefin.com/wp-content/files_mf/stainlesssteels.pdf, [Accessed: $2017-07-21]$

[35] Boehlerstahl GmbH \& Co KG, Time-Temperature-TransformationDiagram for 1. 4021, p. 7, Available from: http://www.bohler-bleche. com/deutsch/files/downloads/N320DE.pdf [Accessed: 2017-04-18]

[36] Data Sheet of Crofer 22 APU, available from: http://www.vdmmetals.com/fileadmin/user_upload/Downloads/Data_Sheets/ Datenblatt_VDM_Crofer_22_APU.pdf, p. 2 [Accessed: 2017-08-09]

[37] G. Kunschert, PhD-thesis, TU Darmstadt, 2009, p. 22.

[38] T. Gietzelt, V. Toth, A. Huell, R. Dittmeyer, Adv. Eng. Mater. 2017, 19.

[39] H. J. Frost, M. F. Ashby, Deformation-Mechanism Maps, The Plasticity and Creep of Metals and Ceramics, chapter 7, Figure 7. 2, Available from: http://engineering.dartmouth.edu/defmech/ 2 [Accessed: 2017-04-18]

[40] DIN EN ISO 1302, Geometrische Produktspezifikation (GPS) - Angabe der Oberflächenbeschaffenheit in der technischen Produktdokumentation, 2002.

[41] DIN EN 10131, Kaltgewalzte Flacherzeugnisse ohne Überzug und mit elektrolytischem Zink- oder Zink-Nickel-Überzug aus weichen Stählen sowie aus Stählen mit höherer Streckgrenze zum Kaltumformen Grenzabmaße und Formtoleranzen, 2006.

[42] DIN EN ISO 9444-2, Kontinuierlich warmgewalzter nichtrostender Stahl - Grenzabmaße und Formtoleranzen - Teil 2: Warmbreitband und Blech, 2009.

[43] Data-base WIAM-metallinfo by IMA Materialforschung und Anwendungstechnik $\mathrm{GmbH}$, Dresden. 